\title{
Comparison of Extraction Methods for Kahweol and Cafestol Analysis in Roasted Coffee
}

\author{
Rafael C. E. Dias, ${ }^{*}, a$ Adelia F. de Faria, ${ }^{b}$ Adriana Z. Mercadante, ${ }^{b}$ \\ Neura Bragagnolo ${ }^{b}$ and Marta de T. Benassi ${ }^{c}$
}

${ }^{a}$ Instituto Federal Catarinense,Campus Araquari, CP 21, 89245-000 Araquari-SC, Brazil

${ }^{b}$ Faculdade de Engenharia de Alimentos, Universidade Estadual de Campinas, CP 6121, 13083-862 Campinas,SP, Brazil

'Departamento de Ciência e Tecnologia de Alimentos, Universidade Estadual de Londrina, CP 6001, 86051-970 Londrina,PR, Brazil

\begin{abstract}
Caveol e cafestol, diterpenos da fração lipídica do café, têm efeitos conhecidos na saúde humana, como atividade anticarcinogênica e hipercolesterolêmica. Existem divergências quanto às concentrações desses compostos reportadas para café torrado, provavelmente devido aos processos de extração empregados. Assim, quatro métodos de preparo de amostra foram estudados: saponificação direta a quente (SDQ), saponificação direta a frio (SDF); e extração por Bligh e Dyer (BD) ou soxhlet (SO) seguida de saponificação. Teores dos diterpenos e seus dehidroderivados obtidos por cromatografia líquida de alta eficiência acoplada a detector de arranjo de diodos e espectrometria de massa (HPLC-DAD-MS/MS) e perfis cromatográficos de café torrado, obtidos pelos quatro métodos, foram comparados. SDQ foi mais eficiente quanto à extração, mostrando melhor separação dos picos cromatográficos e teores de 930,2 $( \pm 36,8), 113,2( \pm 4,7), 568,6( \pm 16,6)$ e 87,1 ( $\pm 3,7) \mathrm{mg} 100 \mathrm{~g}^{-1}$ para caveol, dehidrocaveol, cafestol e dehidrocafestol, respectivamente. O extrato SDQ apresentou teores de diterpenos (caveol e cafestol) $15 \%$ superiores àqueles obtidos por SDF e até $88 \%$ maiores que pelos métodos SO e BD.
\end{abstract}

Kahweol and cafestol, diterpenes from the unsaponifiable fraction of coffee, present known effects on human health such as anticarcinogenic and hipercholesterolemic activities. There are discrepancies regarding the levels reported for these compounds in roasted coffee, probably due to the extraction processes. Therefore, four sample preparation methods were studied: direct hot saponification (DHS), direct cold saponification (DCS); and Bligh and Dyer (BD) or Soxhlet (SO) extraction followed by saponification. The levels of diterpenes and their dehydro derivatives obtained by high performance liquid chromatography with diode array and mass spectrometry detectors (HPLC-DAD-MS/MS) and the chromatographic profiles of roasted coffee, obtained by these four methods, were compared. DHS was more efficient for extraction, showing better separation of chromatographic peaks and levels of 930.2 $( \pm 36.8), 113.2( \pm 4.7), 568.6( \pm 16.6)$ and 87.1 ( \pm 3.7$) \mathrm{mg} 100 \mathrm{~g}^{-1}$ for kahweol, dehydrokahweol, cafestol and dehydrocafestol, respectively. The DHS extract presented a diterpene content (kahweol and cafestol) 15\% superior to that of DCS and up to $88 \%$ superior than using SO and BD methods.

Keywords: direct saponification; soxhlet; Bligh and Dyer; diterpenes; dehydroditerpenes

\section{Introduction}

Diterpenes are a group of compounds present in the unsaponifiable matter of the lipid content of coffee, where kahweol and cafestol, two pentacyclic alcohols, are their main representatives. The roasting process,

*e-mail: rafael.rafaeltam@gmail.com however, may produce small amounts of diterpene dehydro derivatives. ${ }^{1-3}$ Positive effects for human health such as antioxidant, anti-inflammatory and hepatoprotective (against cancer) activities as well as negative factors such hypercolesterolemic activity have been attributed to diterpenes. ${ }^{4-6}$ Furthermore, kahweol and cafestol have been described as potential discriminants between coffee species (Coffea arabica and Coffea canephora). ${ }^{7,8}$ 
Methodologies applying hot and cold procedures are widely used for lipid extraction. The soxhlet method (SO), ${ }^{9}$ a classical approach, involves the use of extractor equipment, where hot solvent (close to its boiling temperature) passes through the sample for an extended time (generally, from 5 to $8 \mathrm{~h}$ ). Despite being the official method of AOAC, ${ }^{10}$ it may lead to the degradation of thermo-sensible compounds due to their long period of heat exposure. ${ }^{3,11}$ The Bligh and Dyer method(BD),${ }^{12}$ which consists of a cold extraction with a mixture of chloroformmethanol, does not require any special equipment, and the analysis is faster. However, volatile and toxic solvents are used in this methodology. BD and SO methods allow for the estimation of the lipid content and produce extracts for the further analysis of several lipophilic compounds of interest. Besides these more conventional extraction techniques, alternative methods based on solvent volume reduction have been proposed as solid phase extraction, matrix solid phase dispersion, supercritical fluid extraction and microwave assisted extraction and QuEChERS (Quick, Easy, Cheap, Effective, Rugged and Safe).$^{13,14,15}$ However, in spite of the advantages considering environmental issues and laboratorial security, they are yet less usual for food analysis as expensive equipment or material is required. ${ }^{13,14}$

Regarding the extraction of unsaponifiable fractions, different approaches are reported in the literature. Some methodologies describe the use of preliminary extraction of lipids as a first step, before saponification, ${ }^{16-21}$ while others suggest direct saponification without pre-extraction. ${ }^{1,22-25}$ Direct saponification, either cold (DCS) or hot (DHS), has been described as the most rapid and efficient alternative for extracting unsaponifiable compounds in different food matrices because it avoids the formation of artifacts ${ }^{26}$ and is also considerably faster and demands lower amounts of solvent. 27,28

A considerable discrepancy between the content of kahweol and cafestol in coffee has been observed: levels from traces to $750 \mathrm{mg} 100 \mathrm{~g}^{-1}$ of sample for kahweol and from less than 10 to $670 \mathrm{mg} 100 \mathrm{~g}^{-1}$ of sample for cafestol. ${ }^{1,5,7,17,20,23,25,29,30}$ Despite the variability in raw materials, to which the differences found in diterpene levels could be partially attributed, the diversity of extraction methods is outstanding. The literature describes the occurrence of decomposition products from diterpenes in roasted coffee, ${ }^{3}$ nevertheless, it is not known whether such components could be formed during the roasting process or simply correspond to the artifacts of an inefficient analytic extraction.

The aim of this work was to evaluate the influence of different extraction methods on the determination of kahweol and cafestol contents in roasted coffees using high performance liquid chromatography with diode array and mass spectrometry detectors (HPLC-DAD-MS/MS). The standard method, direct hot saponification (DHS), was compared with direct cold saponification (DCS) and hot (SO) and cold (BD) preliminary extractions of lipids followed by saponification. The efficiency and the advantages of each procedure were compared.

\section{Experimental}

\section{Solvents and standards}

The following reagents were used for the analyses: anhydrous sodium sulphate ACS 100\% (Synth, São Paulo, Brazil); chloroform p.a. (Merck, Darmstadt, Germany); ethanol 96\% (Merck, Darmstadt, Germany); methanol p.a. (Merck, Darmstadt, Germany); potassium hydroxide $(\mathrm{KOH})$ analytical grade (Merck, Darmstadt, Germany); standards of kahweol and cafestol (Axxora, San Diego, USA), purity $\geq 98 \%$, certified by Alexis Biochemicals (Lausanne, Switzerland); methyl tert-butyl ether (MTBE), spectroscopic grade (Merck, Darmstadt, Germany); water purification system (Milli-Q, Millipore; Billerica, USA).

\section{Sample preparation}

Arabica coffee beans (cv. Iapar-59, derived from cross of Villa Sarchi × Timor Hybrid), were collected in Londrina City in Parana State, Brazil at the Instituto Agronômico do Paraná (IAPAR) located at latitude $23^{\circ} 08^{\prime} 47^{\prime \prime} \mathrm{S}$ and altitude $560 \mathrm{~m}$, with an average annual temperature of 22 to $23^{\circ} \mathrm{C}$. Cherry fruits were manually selected, washed and sun-dried on a patio. The green coffee beans were processed and standardized in grade 16 size sieves $(6.5 \mathrm{~mm})$, and all defective beans were removed. The coffee beans $(0.50 \mathrm{~kg})$ were roasted (Rod-Bel roaster, Brazil) at $190-230{ }^{\circ} \mathrm{C}$ until reaching the weight loss of $20 \%(\mathrm{~m} / \mathrm{m})$, corresponding to dark roasting. After roasting and grinding to a particle size of $0.500 \mathrm{~mm}$ (sieve size ABNT 35), the samples presented $2.4 \pm 0.1 \mathrm{~g} 100 \mathrm{~g} \mathrm{~g}^{-1}$ moisture, $29.0 \pm 0.4$ lightness and $50.1 \pm 2.1$ hue. The color was obtained by a color-guide portable colorimeter (BYK-Gardner, USA) in triplicate and the moisture was evaluated in a halogen moisture analyzer (HB43-S model, Mettler Toledo, UK) in duplicate.

Five genuine replicates were created for each method (DHS, DCS, SO, BD). The procedures were compared with respect to levels of kahweol and cafestol and their dehydroderivatives obtained by HPLC-DAD-MS/MS, as well as the chromatographic profile (resolution and peak separation). The applicability of each method was also taken into account, considering the facility and rapidness 


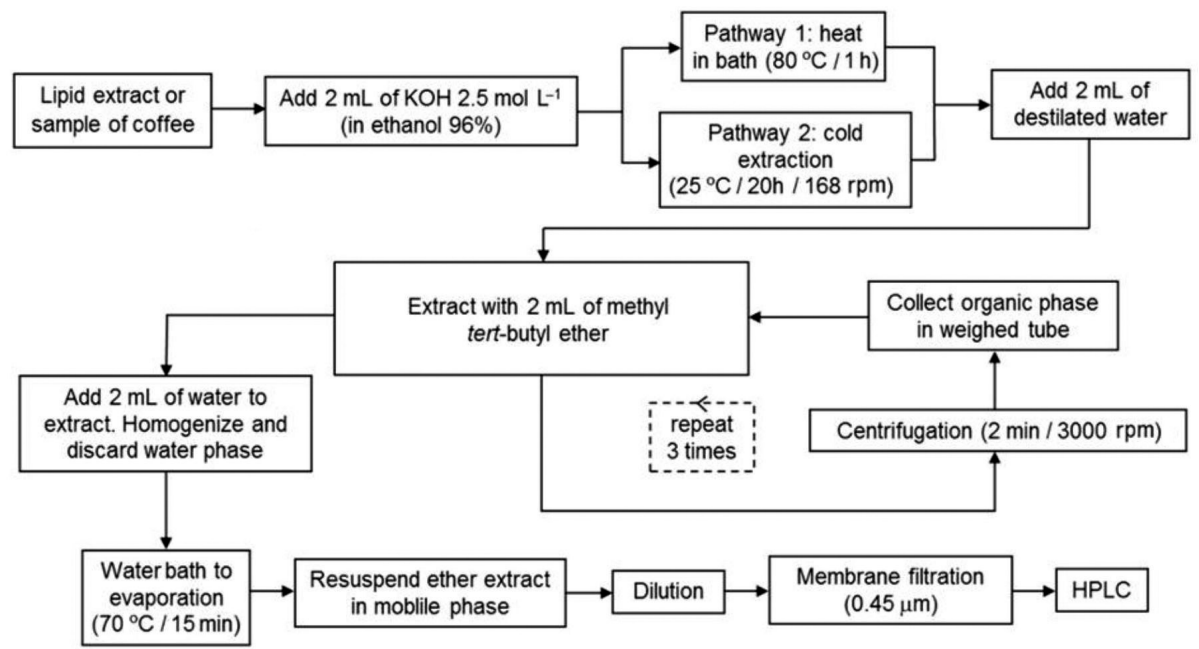

Figure 1. Flowchart of the unsaponifiable matter extraction from roasted coffee. Samples prepared by hot saponification of the lipid extracts obtained through soxhlet (SO) and Bligh and Dyer (BD) (pathway 1), directly from the roasted coffee through direct hot saponification (pathway 1) or direct cold saponification (pathway 2)

of extraction of the unsaponifiable matter, use of a lower amount of solvent, and the level of danger presented to the analyst.

\section{Extraction and saponification}

An overview of the employed procedures is shown in Figure 1.

\section{Direct hot saponification (DHS)}

The method described by Dias et al. ${ }^{1}$ was employed and consisted of weighing, in a test tube, $0.200 \mathrm{~g}$ of roasted arabica coffee and then adding $2 \mathrm{~mL}$ of $\mathrm{KOH}$ solution for direct sample saponification. After a $1 \mathrm{~h}$ water bath at $80^{\circ} \mathrm{C}$, the unsaponifiable matter was extracted using MTBE and washed with water (pathway 1, Figure 1).

\section{Direct cold saponification (DCS)}

This method was based on the DHS extraction conditions used by Bandeira et al. ${ }^{27}$ and Mariutti, Nogueira and Bragagnolo. ${ }^{28}$ Two milliliters of a $\mathrm{KOH}$ solution were added to $0.200 \mathrm{~g}$ of roasted and ground coffee sample in a sealed Erlenmeyer flask $(25 \mathrm{~mL})$ and then stirred for $20 \mathrm{~h}$ (Orbital agitator, MA-140/CFT) at $168 \mathrm{rpm}$ and $25^{\circ} \mathrm{C}$ (pathway 2, Figure 1). After saponification, extraction was performed (Figure 1).

\section{Hot lipid extraction by soxhlet (SO)}

The procedure was based on the method used by Kölling-Speer et $a l .{ }^{18}$ for coffee (green beans and roasted coffee) lipid extraction through soxhlet for further analyses of diterpenes. Five grams of roasted ground coffee in an extraction cartridge were placed in a flat-bottomed flask $(250 \mathrm{~mL})$. The extraction was carried out in a soxhlet extractor setup for $6 \mathrm{~h}$ of reflux with $150 \mathrm{~mL}$ of MTBE at the solvent boiling temperature $\left(55\right.$ to $60{ }^{\circ} \mathrm{C}$ ). After evaporating the solvent in a rotary evaporator (Büchi R-114), the mass of the lipid extract was gravimetrically determined. One portion of the extract was submitted to saponification. MTBE $(10 \mathrm{~mL})$ was added to a flat-bottomed flask to obtain a solution of known concentration, and one milliliter of this solution was transferred to a test tube. The solvent was evaporated (at $50^{\circ} \mathrm{C}$ for $15 \mathrm{~min}$ ) and saponification with a $\mathrm{KOH}$ solution and the extraction of diterpenes were performed (pathway 1, Figure 1).

\section{Lipid extraction through Bligh and Dyer (BD)}

For $10.0 \mathrm{~g}$ of sample, with a moisture content of $2.4 \%(\mathrm{~m} / \mathrm{m}),{ }^{12}$ the solvent ratio used was $10: 20: 8$ (chloroform:methanol:water) $(\mathrm{v} / \mathrm{v} / \mathrm{v})$. Five grams of roasted coffee was weighed into an Erlenmeyer flask $(250 \mathrm{~mL})$, followed by the addition of $5 \mathrm{~mL}$ of chloroform, $10 \mathrm{~mL}$ of methanol and $4 \mathrm{~mL}$ of distilled water. The flask was sealed and stirred for $10 \mathrm{~min}$ at $168 \mathrm{rpm}$ in a shaker (Orbital, MA-140/CFT). Then $5 \mathrm{~mL}$ of chloroform and $5 \mathrm{~mL}$ of $1.5 \%$ sodium sulfate (drying agent) were added, and the mixture was stirred for another $30 \mathrm{~min}$ at the same rotation. The solution was transferred to a centrifuge tube using $5 \mathrm{~mL}$ of chloroform. After centrifugation (3 min at $2880 \mathrm{rpm}$ ), the bottom phase with chloroform, which contained the lipid fraction, was removed and filtered using filter paper with $1.0 \mathrm{~g}$ of anhydrous sodium sulfate to remove the residual water. The filtrate, collected in a volumetric flask of a standardized weight, was concentrated in a vacuum rotary evaporator (Büchi R-114) up to $40{ }^{\circ} \mathrm{C}$ and weighed after $24 \mathrm{~h}$ in a desiccator. The amount of lipid in $100 \mathrm{~g}$ of 
the sample was calculated, and this extract was submitted to further extraction.

Methyl tert-butyl ether $(10 \mathrm{~mL})$ was added to the flat-bottomed flask, and $1 \mathrm{~mL}$ of a solution of a known concentration was transferred to a test tube. The solvent was evaporated ( $50^{\circ} \mathrm{C}$ for $15 \mathrm{~min}$ ), followed by saponification with a $\mathrm{KOH}$ solution and the extraction of diterpenes (pathway 1, Figure 1).

\section{Chromatographic analysis}

The identity and purity of the peaks were verified by HPLC-DAD-MS/MS using a Shimadzu liquid chromatograph (Kyoto, Japan) with a quaternary solvent delivery system (LC20AD) and degasser (DGU20A5) and a $20 \mu \mathrm{L}$ Rheodyne fixed-loop injector (Rheodyne LCC, Rohnert Park, EUA). The system was connected in series to a diode array detector (DAD) (Shimadzu, model SPD-M20A) and a mass spectrometer with an ion-trap analyzer and atmospheric pressure chemical ionization (APCI) source from Bruker Daltonics, model Esquire 4000 (Bremen, Germany). The mass spectrometer conditions were previously optimized using standards and coffee samples roasted at different degrees (data not published). The MS parameters were set as follows: positive mode; corona current of $4.0 \mu \mathrm{A}$; source temperature of $450{ }^{\circ} \mathrm{C}$; dry nitrogen gas, $\mathrm{N}_{2}$, temperature, $350{ }^{\circ} \mathrm{C}$; flow, $4 \mathrm{~L} \mathrm{~min}^{-1}$; nebulizer pressure, $60 \mathrm{psi}$; MS/MS fragmentation energy, $1.4 \mathrm{~V}$. The mass spectra were acquired over an $\mathrm{m} / \mathrm{z}$ (massto-charge ratio) scan range from 100 to 700 (scan mode).

The quantification was carried out in a Waters liquid chromatograph with a quaternary solvent manager (Waters, model 600), diode array detector (Waters, model 996), Rheodyne injector valve with a $20 \mu \mathrm{L}$ loop, online degasser (Waters) and a Millennium (Waters) acquisition and data processing system. A Spherisorb ODS-1 column (Waters, Milford, USA) measuring $250 \times 4.6 \mathrm{~mm}$ and $5 \mu \mathrm{m}$ in diameter and isocratic elution (acetonitrile:water 55:45 v/v; $\left.0.9 \mathrm{~mL} \mathrm{~min}^{-1}\right)$ under controlled temperature condition $\left(25^{\circ} \mathrm{C}\right)$ were used. ${ }^{1}$ The run time ( $35 \mathrm{~min}$ ) was extended beyond the retention time $\left(t_{R}\right)$ of the last diterpene of interest (cafestol, $t_{R}=15.5 \mathrm{~min}$ ) to allow for the elution of other compounds and thus accommodate the different extraction procedures that were tested. The chromatographic conditions were the same for quantification of compounds and for the mass spectrometry analysis. The resolution factor $(\mathrm{R})$ between two peaks of interest was also calculated.

The quantification was carried out using external calibration curves with 6 points in triplicate $\left(R^{2} \geq 0.999\right.$, $\mathrm{p}<0.001)$. The spectra were acquired at wavelengths between 190 and $400 \mathrm{~nm}$ and processed at the maximum wavelength of each diterpene or peak of interest. Quantification of kahweol and dehydrokahweol were carried out at $290 \mathrm{~nm}$, and of cafestol and dehydrocafestol at $230 \mathrm{~nm}$. It was considered that the dehydro derivatives presented the same molar absorptivity of the corresponding diterperne alcohol (kahweol or cafestol). ${ }^{24}$

\section{Statistical analysis}

The data regarding the concentration of compounds under study were submitted to analysis of variance (ANOVA, Tukey test for $\mathrm{p} \leq 0.05$ ), considering the extraction method as the source of variation, using the software Statistica version 6.0. ${ }^{31}$

\section{Results and Discussion}

The chromatographic profiles for all sample preparation methods were similar (Figure 2). It should be emphasized that the peak intensities (Figure 2) between the procedures should not be directly compared because they were analyzed under different dilutions.

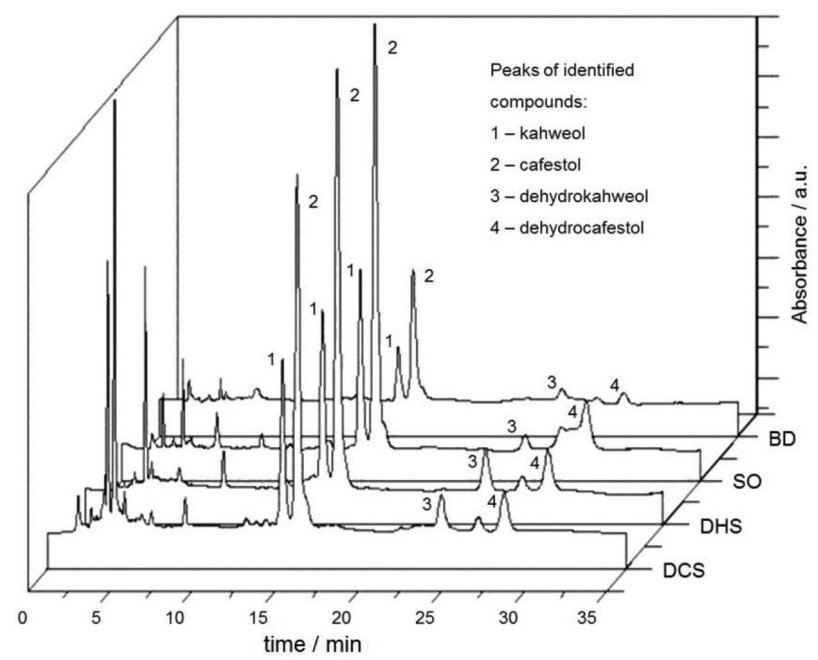

Figure 2. Typical chromatogram (processed at $230 \mathrm{~nm}$ ) of diterpenes compounds of roasted coffee samples prepared by direct hot saponification (DHS) or direct cold saponification (DCS) and by hot saponification of the lipid extracts obtained through soxhlet (SO) or Bligh and Dyer (BD).

As shown in Figure 2, kahweol $\left(t_{R}=14.5\right.$ min, peak 1) and cafestol ( $t_{R}=15.5 \mathrm{~min}$, peak 2$)$ showed well-defined sharp peaks with separation with satisfactory resolution ( $\mathrm{R}=1.6$ ), considering the great similarity between the structures of such compounds. The worst separation between peaks 3 and 4 (Figure 2), which were identified as dehydro derivatives (Table 1), was verified for the SO method, hindering both the identification and quantification in the analysis through MS. 
Table 1. Characteristics of diterpenes from roasted coffee beans obtained by HPLC-DAD-MS/MS

\begin{tabular}{|c|c|c|c|c|c|}
\hline Peak $^{\mathrm{a}}$ & $R_{\mathrm{T}} / \min$ & $\lambda_{\max } / \mathrm{nm}$ & {$[\mathrm{M}+\mathrm{H}]^{+} / \mathrm{m} / z$} & $\mathrm{MS} / \mathrm{MS}^{\mathrm{b}} / \mathrm{m} / z$ & Compound \\
\hline 1 & 14.7 & 288 & 315 & $\begin{array}{c}297[\mathrm{M}+\mathrm{H}-18]^{+} \\
279[\mathrm{M}+\mathrm{H}-18-18]^{+} \\
145,133\end{array}$ & \\
\hline 2 & 15.5 & 225 & 317 & $\begin{array}{c}299[\mathrm{M}+\mathrm{H}-18]^{+}, \\
281[\mathrm{M}+\mathrm{H}-18-18]^{+}, \\
147,131\end{array}$ & \\
\hline 3 & 26.5 & 291 & 297 & $279,145,133$ & \\
\hline 4 & 27.5 & 223 & 299 & $281,147,131$ & \\
\hline
\end{tabular}

${ }^{a}$ Numbered according to Figure 2 ; ${ }^{\text {s }}$ second fragmentation from the protonated molecule.

Regarding the efficiency of lipid extraction, an overestimation was observed for SO $(18.6 \pm 0.01 \mathrm{~g}$ of lipids $100 \mathrm{~g}^{-1}$ of coffee, dry base). In the literature, the highest values ever reported for the total lipid level of dark roasting arabica coffee approach $15.4 \%$. $^{3,29,32}$ The solvent used in the SO method carried colored compounds with greater solubility in the organic solvent (MTBE). The extraction of interfering compounds was probably also enhanced by the long exposure time of the solvent and the reflow operations. This could be the reason for the co-elution of compounds between peaks 3 and 4 even after the saponification, extraction and cleaning procedures (Figure 2).

The peaks were identified according to the following combined information: standard addition method, UV-Vis spectrum and mass spectrum compared with authentic standards (Table 1 and Figure 2). In addition, the MS/MS spectra confirmed the assignment of the protonated molecule $[\mathrm{M}+\mathrm{H}]^{+}$.

For peak 2 (Figure 2), the $[\mathrm{M}+\mathrm{H}]^{+}$at $\mathrm{m} / \mathrm{z} 317$ and MS/MS fragments at $m / z 299$ and $m / z 281$ due to the loss, respectively, of one and two molecules of water and another MS/MS fragment at $m / z 147\left[\mathrm{M}+\mathrm{H}-\mathrm{C}_{10} \mathrm{H}_{18} \mathrm{O}_{2}\right]^{+}$confirmed the identity of cafestol (Table 1 and Figure 3). Kahweol (peak 1), which presents one more double bond in the kaurene ring and two less hydrogen atoms, showed analogous fragments, with $2 \mathrm{u}$ less than the fragments of cafestol (Table 1).

Peaks 3 and 4 (Figure 2) were identified as dehydrokahweol and dehydrocafestol, respectively. These dehydro derivatives showed UV-Vis spectra with similar profiles compared to their respective diterpene alcohols,

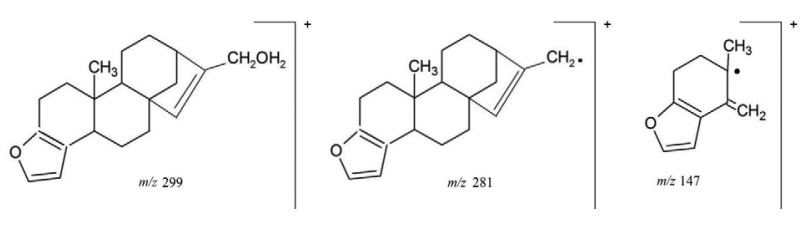

Figure 3. Mass fragments of cafestol (peak 2 of Figure 2).

kahweol and cafestol (Figure 4 and Table 1). The wavelength of maximum absorption $\left(\lambda_{\max }\right)$ depends on the presence of the chromophores in a molecule, especially those with conjugated double bonds. ${ }^{33}$ Despite the double bond created from the output of a water molecule, a specific diterpene and its dehydro derivative had the same number of conjugated double bonds, which resulted in similar $\lambda_{\max }$ values (Table 1 and Figure 4). Furthermore, the protonated molecules

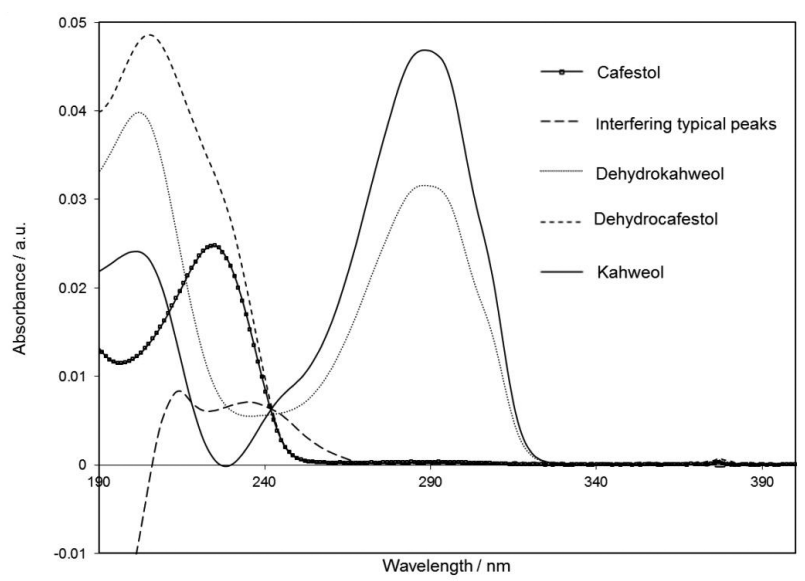

Figure 4. UV-Vis spectra of compounds of interest (peaks 1, 2, 3 and 4 of Figure 2) and interfering (between peaks 3 and 4 of Figure 2). 
$[\mathrm{M}+\mathrm{H}]^{+}$of peaks 3 and 4 showed $18 \mathrm{u}$ less than those of the kahweol and cafestol molecules, respectively, indicating the presence of their respective dehydro derivative compounds. Moreover, the $[\mathrm{M}+\mathrm{H}]^{+}$and MS/MS fragments obtained for the analyzed compounds (Table 1) indicated that both dehydrocafestol and dehydrokahweol presented the same fragmentation patterns shown, respectively, by cafestol and kahweol, which confirms the structural similarities between these compounds.

The unidentified peaks did not present fragments with $\mathrm{m} / \mathrm{z}$ that would indicate a fragmentation mechanism for diterpenes.

The presence of the dehydro derivatives were not observed in previous studies, when an HPLC method and direct hot saponification were used to determine kahweol and cafestol in green coffee. ${ }^{1}$ In the present work, the occurrence of dehydrokahweol and dehydrocafestol in the four methods indicated that they were not artifacts of analytic extraction but a product of the roasting process of coffee.

Comparing the levels of kahweol, cafestol and their derivatives through different extractions, it was verified that direct saponification was more effective than the methodologies that pre-extracted the lipids before saponification. Both BD and SO demonstrated low efficiency with regard to the extraction of the four compounds identified, resulting in much lower levels than those obtained through direct saponification (DHS, DCS) (Table 2).

In addition to the diversity among the methods, differences in the extraction could also be attributed to the different solvents used. Considering the selectivity and efficiency of extraction, organic solvents should be characterized according to their ability to interact with the solute either as a dipole (dipolarity, $\pi^{*}$ ), as a proton acceptor (acidity, $\alpha$ ), and as a proton donor (basicity, $\beta)^{34}$ and the polarity index. ${ }^{35,36}$ The polarity indexes of MTBE, methanol and chloroform are 2.5, 5.1 and 4.1, respectively. The solvatochromic parameters for MTBE were not determined, so the values of diisopropyl ether were considered. Diisopropyl ether $\left(\alpha 0.00 ; \beta 0.64 ; \pi^{*} 0.36\right)$ presents different parameters compared to methanol $\left(\alpha 0.43 ; \beta 0.29 ; \pi^{*} 0.28\right)$ and chloroform $(\alpha 0.43 ; \beta 0.00$; $\pi^{*} 0.57$ ). However, similar results (low levels of diterpenes) were observed for both BD and SO, which indicated that the solvents were not primarily responsible for the low efficiency of the $\mathrm{BD}$ and $\mathrm{SO}$ extractions.

For SO, at first, problems would be expected regarding compound degradation because, according to the literature, the reflux of hot solvent for several hours favors the peroxidation and hydrolysis reactions, which could later jeopardize the analytical results. ${ }^{11}$ The literature also
Table 2 Levels of diterpene compounds in samples of roasted coffee beans, obtained by different sample preparations

\begin{tabular}{lcccc}
\hline Diterpene & $\begin{array}{c}\text { Extraction } \\
\text { method }^{\mathrm{a}}\end{array}$ & Mean $^{\mathrm{b}}$ & $\mathrm{SD}$ & $\mathrm{RSD} / \%$ \\
\hline \multirow{3}{*}{ Kahweol } & DHS & $930.2 \mathrm{a}$ & 36.8 & 3.9 \\
& DCS & $789.8 \mathrm{~b}$ & 14.5 & 1.8 \\
& SO & $192.4 \mathrm{c}$ & 8.31 & 4.3 \\
& $\mathrm{BD}$ & $101.6 \mathrm{~d}$ & 4.20 & 4.1 \\
\hline \multirow{4}{*}{ Dehydrokahweol } & DHS & $113.2 \mathrm{a}$ & 4.66 & 4.1 \\
& DCS & $111.5 \mathrm{a}$ & 1.76 & 1.5 \\
& SO & $22.7 \mathrm{~b}$ & 1.42 & 6.2 \\
Cafestol & BD & $14.1 \mathrm{c}$ & 0.13 & 0.9 \\
\hline & DHS & $568.6 \mathrm{a}$ & 16.6 & 2.9 \\
& SDF & $483.1 \mathrm{~b}$ & 15.0 & 3.1 \\
& SO & $126.3 \mathrm{c}$ & 10.3 & 8.1 \\
& BD & $68.6 \mathrm{~d}$ & 0.78 & 1.1 \\
\hline \multirow{4}{*}{ Dehydrocafestol } & DHS & $87.1 \mathrm{a}$ & 3.74 & 4.2 \\
& DCS & $86.2 \mathrm{a}$ & 1.77 & 2.0 \\
& SO & $18.1 \mathrm{~b}$ & 1.07 & 5.9 \\
& BD & $11.1 \mathrm{c}$ & 0.26 & 2.4 \\
\hline
\end{tabular}

${ }^{\mathrm{a}}$ Direct hot saponification (DHS), direct cold saponification (DCS), extraction through soxhlet with hot saponification (SO) and extraction through Bligh and Dyer with hot saponification (BD); ${ }^{b}$ Mean concentration (mg $100 \mathrm{~g}^{-1}$ of sample, dry basis) of 5 repetition of extraction. Different letters in the column indicate significant differences among the means for each compound; SD: standard deviation; RSD: relative standard deviation.

indicates that kahweol could be subjected to degradation and produce dehydro derivatives when submitted to high temperature for long periods, e.g., during intense coffee roasting. ${ }^{3,24}$ It was observed, however, that both hot extraction (SO) and cold extraction (BD) of lipid for further saponification presented inadequate results, so the lower results obtained for SO and BD could not be mainly attributed to thermal degradation. Moreover, it was also verified that cafestol and even kahweol, which presents a structure that is more susceptible to oxidation, were not affected by temperature and time of exposition $\left(80^{\circ} \mathrm{C}, 1 \mathrm{~h}\right)$ applied in DHS (Table 2). These results indicate that direct saponification is more appropriate in ensuring the efficient quantification of the diterpenes from roasted coffee.

Considering the amount of solvent, SO demands a minimum of $150 \mathrm{~mL}$ of MTBE, which cannot be reused for the same analysis, while $\mathrm{BD}$ requires $10 \mathrm{~mL}$ of MTBE and approximately $20 \mathrm{~mL}$ of methanol and chloroform. Because an extraction step is not followed in the DHS and DCS procedures, these methods are more economic and less dangerous to the analyst. Moreover, direct hot saponification has also proved to be advantageous with respect to speed of processing. Almost $24 \mathrm{~h}$ was necessary to complete sample preparation by DCS, which is much longer than the $4 \mathrm{~h}$ (six times) required by DHS. 
By comparing the results from the direct saponification methods, we observed the same efficiency for dehydroditerpene extraction for both procedures; however, the hot technique (DHS) showed better performance for kahweol and cafestol. This result indicates that the greatest extraction efficiency at high temperatures overlaps with the possible degradation that can occur at this temperature.

Recovery tests were carried out to ensure the efficiency of the DHS procedure. Kahweol and cafestol standards were added to the sample before analysis in an amount of approximately $50 \%$ of the content (duplicate). Good recovery were observed: $109 \%$ for kahweol and $106 \%$ for cafestol. Kolling-Speer et al. ${ }^{18}$ reported recovery of $80.5 \%$ for cafestol, using the same procedure of test. There are no reports of recovery for kahweol.

A mean level of $930 \mathrm{mg}$ of kahweol $100 \mathrm{~g}^{-1}$ of sample was found through DHS, nearly $15 \%$ superior to the value obtained through DCS (790 mg $100 \mathrm{~g}^{-1}$ of sample). Cafestol presented a similar difference as follows: 568 (DHS) and $483 \mathrm{mg} 100 \mathrm{~g}^{-1}$ of sample (DCS) (Table 2). However, the difference among levels of diterpenes considering the methodologies by direct saponification and those with pre-extraction for subsequent saponification, $\mathrm{SO}$ and BD, was even greater: $75-87.5 \%$. For arabica roasted coffee, the literature describes concentrations of kahweol that reach up to $870 \mathrm{mg} 100 \mathrm{~g} \mathrm{~g}^{-1}$ and a maximum of $700 \mathrm{mg} 100 \mathrm{~g}^{-1}$ for cafestol, $, 116,17,19,20,23,30$ corroborating the results described in this work for extraction through DHS.

Some papers have investigated the stability of compounds from the unsaponifiable matter at the temperature of saponification. Bandeira et $a l .{ }^{27}$ tested several procedures of extraction to evaluate cholesterol through HPLC: direct hot saponification; lipid extraction (Folch method) followed by hot saponification; and direct cold saponification. The last procedure has presented a chromatograph with fewer interfering compounds and a higher cholesterol peak area and is also very easy to execute and uses a smaller amount of solvent.

Other authors have reported good results regarding the use of DHS for diterpenes. Roos et al..$^{22}$ and Urgert et al. ${ }^{23}$ used an ethanol solution of sodium hydroxide for $1 \mathrm{~h}$ at $80^{\circ} \mathrm{C}$ for the direct saponification of lipids from green coffee beans. After the extraction of the unsaponifiable matter with diisopropyl ether and clean up with water, adequate values for kahweol and cafestol in fresh fruits of Coffea canephora, C. liberica, C. congensis and C. arabica were obtained through gas chromatography. De Souza et al..$^{25}$ found up to $800 \mathrm{mg}$ of kahweol 100 $\mathrm{g}^{-1}$ sample and up to $550 \mathrm{mg}$ of cafestol $100 \mathrm{~g}^{-1}$ for 38 roasted and ground commercial coffee using direct hot saponification.
The direct hot saponification (DHS) method, with the addition of a saponificating solution ( $\mathrm{KOH}$ in ethanol) to the sample and $1 \mathrm{~h}$ heating at $80^{\circ} \mathrm{C}$, was considered to be, overall, the most efficient for the extraction of diterpenes for further quantification.

\section{Conclusions}

The direct hot saponification (DHS) was observed to be more efficient, quicker and more economical for extracting diterpenes from roasted coffee. For DHS, the levels of kahweol and cafestol were nearly $15 \%$ higher than those obtained by cold saponification (DCS) and up to $88 \%$ superior to those obtained through preliminary extractions of the lipid fraction (SO and $\mathrm{BD}$ ) followed by saponification.

\section{Acknowledgments}

The authors acknowledge the Brazilian foundations National Council for Technological and Scientific Development (CNPq), São Paulo Research Foundation (FAPESP) and Brazilian Federal Agency for Support and Evaluation of Graduate Education (CAPES) for financial support.

\section{References}

1. Dias, R. C. E.; Campanha, F. G.; Vieira, L. G. E.; Ferreira, L. P.; Pot, D.; Marraccini, P.; Benassi, M. T.; J. Agric. Food Chem. 2010, 58, 88.

2. Scharnhop, H.; Winterhalter, P.; J. Food Comp. Anal. 2009, 22, 233.

3. Speer, K.; Kölling-Speer, I.; Braz. J. Plant Physiol. 2006, 18, 201.

4. Kim, H. G.; Hwang, Y. P.; Jeong, H. G.; Toxicol. Lett. 2009 , 187, 28.

5. Nkondjock, A.; Cancer Lett. (N. Y., NY, U. S.) 2009, 227, 121.

6. Cavin, C.; Holzhäuser, D.; Scharf, G.; Constable, A.; Huber, W. W.; Schilter, B.; Food Chem. Toxicol. 2002, 40, 1155.

7. Campanha, F. G.; Dias, R. C. E.; Benassi, M. T.; Coffee Sci. 2010, 5, 87; De Souza, R. M. N.; Benassi, M. T.; J. Braz. Chem. Soc. 2012, 23, 1347.

8. Kemsley, E. K.; Ruault, S.; Wilson, R. H.; Food Chem. 1995, $54,321$.

9. Soxhlet, F.; Polytechnisches J. 1879, 232, 461.

10. Association of Official Analytical Chemists. (AOAC); Official Methods of Analysis. Method No. 920.85, 15 th ed.; AOAC: Washington, USA, 1990.

11. Brum, A. A. S.; Arruda, L. F.; Regitano-d'Arce, M. A. B.; Quim. Nova 2009, 32, 849. 
12. Bligh, E. G.; Dyer, W. J.; Can. J. Biochem. Physiol. 1959, 37, 911.

13. Mendiola, J. A.; Herrero, M.; Cifuentes, A.; Ibañez, E.; J. Chromatogr., A 2007, 1152, 234.

14. Prestes, O. D.; Friggi, C. A.; Adaime, M. B.; Zanella, R.; Quim. Nova 2009, 32, 1620.

15. Bojko, B.; Cudjoe, E.; Gómez-Ríos, G. A.; Gorynski, K.; Jiang, R.; Reyes-Garcés, N.; Risticevic, S.; Silva, E. A. S.; Togunde, O.; Vuckovic, D.; Pawliszyn, J.; Anal. Chim. Acta 2012, 750, 132.; Lanças, F. M.; Extração em Fase Sólida (SPE), $4^{\text {th }}$ ed.; RiMa: São Carlos, Brasil, 2004; Anastassiades, M.; Lehotay, S.; Stajnbaher, D.; Schenck, F. J.; J. AOAC Int. 2003, 86, 412.

16. Araújo, J. M. A; Sandi, D.; Food Chem. 2006, 101, 1087.

17. Rubayiza, A. B.; Meurens, M.; J. Agric. Food Chem. 2005, 53, 4654.

18. Kölling-Speer, I.; Strohschneider, S.; Speer, K.; J. High Resol. Chromatogr. 1999, 22, 43.

19. Lercker, G.; Frega, N.; Bocci, F.; Rodriguez-Estrada, M. T.; Chromatographia 1995, 41, 29.

20. Frega, N.; Bocci, F.; Lercker, G.; J. High Resol. Chromatogr. 1994, 17, 303.

21. Pettitt Jr., B. C.; J. Agric. Food Chem. 1987, 35, 549.

22. Roos, B.; van der Weg, G.; Urgert, R.; van de Bovenkamp, P.; Charrier, A.; Katan, M. B.; J. Agric. Food Chem. 1997, 45, 3065.

23. Urgert, R.; van der Weg, G.; Kosmeijer-Schuil, T. G.; van de Bovenkamp, P.; Hovenier, R.; Katan, M. B.; J. Agric.Food Chem. 1995, 43, 2167.

24. Dias, R. C. E.; Faria, A. F.; Mercadante, A. Z.; Bragagnolo, N.; Benassi, M. T.; Diterpenes profile in coffee: influence of roasting process, $242^{\text {nd }}$ National Meeting of the American Chemical
Society, Abstracts of Papers, vol. 242. Denver, 2011. Retrieved February 28, 2012 from: http://abstracts.acs.org/chem/242nm/ program/view.php?obj_id=91648\&terms=.

25. de Souza, R. M. N.; Canuto, G. A. B.; Dias, R. C. E.; Benassi, M. T.; Quim. Nova 2010, 33, 885.

26. Saldanha, T.; Sawaya, A. C. H. F.; Eberlin, M. N.; Bragagnolo, N.; J. Agric. Food Chem. 2006, 54, 4107.

27. Bandeira, C. M.; Ferreira, J. M.; Bragagnolo, N.; Mariutti, L. R. B.; Quim. Nova 2008, 31, 1422.

28. Mariutti, L. R. B.; Nogueira, G. C.; Bragagnolo, N.; J. Agric. Food Chem. 2008, 56, 2913.

29. Lago, R. C. A.; Boletim do CEPPA 2001, 19, 319.

30. Kurzrock, T.; Speer, K.; Food Rev. Int. 2001, 17, 433.

31. Statsoft 6.0; Statistica for Windows: Computer Program Manual; Software Inc.: Tulsa, 2001.

32. Lercker, G.; Caboni, M. F.; Bertacco, G.; Turchetto, E.; Lucci, A.; Bortolomeazzi, R.; Pagani, E.; Frega, N.; Bocci, F.; Industrie Alimentari 1996, 35, 1057.

33. Skoog, D. A.; West, D. M.; Holler, F. J.; Crouch, S. R.; Fundamentals of Analytical Chemistry, $8^{\text {th }}$ ed.; Thomson Brooks-Cole: Boston, USA, 2004.

34. Snyder, L. R.; Carr, P. W.; Rutan, S. C.; J. Chromatogr., A 1993 , 656, 537.

35. Johnson, A. R.; Vitha, M. F.; J. Chromatogr., A 2011, 1218, 556.

36. Fu, C.; Khaledi, M. G.; J. Chromatogr., A 2009, 1216, 1891.

Submitted: July 10, 2012

Published online: March 15, 2013

FAPESP has sponsored the publication of this article. 